References:

[1] Diniz-Freitas $M$ et al., Oral bisphosphonate-related osteonecrosis of the jaws: Clinical characteristics of a series of 20 cases in Spain. Med Oral Pathol Oral Cir Bucal 2012:17:e751.

Disclosure of Interest: None declared

DOI: 10.1136/annrheumdis-2017-eular.2506

\section{AB0823 EVALUATION OF OSTEOPOROSIS AND FRACTURES IN PATIENTS WITH DIABETES MELLITUS TYPE 2: RESULTS OF A 5-YEAR FOLLOW-UP}

V.L. Masenko ${ }^{1}$, A.N. Kokov ${ }^{1}$, S.E. Semenov ${ }^{1}$, T.A. Raskina ${ }^{2}$, O.L. Barbarash ${ }^{1}$. ${ }^{1}$ Federal State Budgetary Scientific Institution Research Institute for Complex Issues of Cardiovascular Diseases; ${ }^{2}$ Kemerovo state medical academy of Federal Agency of Healthcare and Social Development, Kemerovo, Russian Federation

Objectives: The aim of the study is to determine the characteristics of bone mineral density (BMD) and the the prevalence of fractures of the vertebral fractures and long bones in men with diabetes mellitus type 2 on the basis of 5 -year prospective study.

Methods: 251 males (60.56 $\pm 8.7 y e a r s)$ were examined. The patients were divided into 2 groups: patients with type 2 diabetes mellitus $(n=65)$ and patients without disorder of carbohydrate metabolism $(n=186)$. All patients underwent DXAdefinition of BMD $\left(\mathrm{g} / \mathrm{cm}^{2}\right)$, T-score of the spine and bones of the femur. Dynamic observation for 5 years and the determination of vertebral fractures and long bones.

Results: BMD measured in lumbar spine and proximal femur were analyzed. According DXA BMD of femur in patients with diabetes is significantly higher than that of non-diabetics $(0,928[0,847 ; 1,029] ; 0,858[0,7790,928] ; p=0,000005)$. T-score is also higher in diabetics $(-1,47[-2,12 ;-0,63] ;-2,01 \quad[-2,71 ;-1,49]$; $p=0,000020$ ). BMD and T-score of the lumbar vertebrae in diabetic patients was also is significantly higher: BMD (Group I =1,002 [0,902;1,182]; Group II $=0,969[0,879 ; 1,106] ; p=0,008)$. T-score $(-0,94[-1,43 ;-0,05] ;-1,07[-1,54 ;-0,40]$; $\mathrm{p}=0,014)$. After 5 years, spine or long bones fractures marked in 12 patients $(18 \%)$ from I group. In Group II was observed only 5 episodes of bone fracture (2.6\%). Conclusions: BMD in men with diabetes are higher, but they often develop bone fractures. Perhaps this is due to pathological remodeling of bone tissue on a background of metabolic disorders, when bone is more dense, but fragile.

Disclosure of Interest: None declared

DOI: 10.1136/annrheumdis-2017-eular.1124

\section{AB0824 THE METHOD OF CALCULATING THE PROBABILITY OF OSTEOPENIA IN PATIENTS WITH MULTIFOCAL ATHEROSCLEROSIS}

A.N. Kokov ${ }^{1}$, V.L. Masenko ${ }^{1}$, S.E. Semenov ${ }^{1}$, T.A. Raskina ${ }^{2}$, O.L. Barbarash ${ }^{1}$. ${ }^{1}$ Federal State Budgetary Scientific Institution Research Institute for Complex Issues of Cardiovascular Diseases; ${ }^{2}$ Kemerovo state medical academy of Federal Agency of Healthcare and Social Development, Kemerovo, Russian Federation

Objectives: To determine probability of the presence of osteopenic syndrome in patients with multifocal atherosclerosis based on the multislice computed tomography (MSCT) evaluation of vascular calcification.

Methods: 186 male ( $60 \pm 6,7$ years) with multifocal atherosclerosis. All the patients underwent the measurement of BMD with X-ray absorptiometry. Moreover, calcium scores (CS) of coronary and brachiocephalic arteries were obtained using Agatston method.

Results: Among the patients had a high prevalence of osteopenia syndrome (87.1\%). According to X-ray absorptiometry T-score values of lumbar vertebrae $-1.07[-1.54 ;-0.40]$, T-score of the proximal femur $-2.01[-2.71 ;-1.49]$. We also found a large amount of calcification of the coronary arteries according MSCT: calcium score (CS) 471.8 [118.2; 916,8]. Calcification of the carotid arteries in patients of the study group was less pronounced: CS 113.9 [44.5; 300.8], but noted significant direct relationship between the degree of calcification of different vascular beds $(r=0,35, p<0,05)$. We have data on the significant inverse association between bone density and a coronary artery calcification $(r=-0,29$, $\mathrm{p}<0,05)$, and the carotid artery $(\mathrm{r}=-0,22, \mathrm{p}<0,05)$ by using Spearman rank correlations. Factors that affect the probability of osteopenic syndrome (according X-ray absorptiometry) in patients with known rates of calcification of the coronary and carotid arteries were obtained by regression analysis. These factors were coronary CS $(p=0.012)$, carotid CS $(p=0.034)$, the mass of calcifications of the carotid arteries $(p=0.025)$ and the presence of a stenosis of the carotid arteries $(p=0.026)$. The predictive model for estimating the probability of the presence of osteopenia in patients with multifocal atherosclerosis has been is designed using regression coefficients of each of the factors. As a result, ROC-analysis of the area under the ROC-curve for this prediction model was $0.792(p=0.0001)$. The model was tested in the study sample. The specificity of the model was $72.1 \%$, sensitivity of the model was $80.2 \%$.

Conclusions: The study results suggest that indicators of calcification of the carotid and coronary arteries resulting from a routine examination by MSCT of patients with multifocal atherosclerosis have a high predictive capacity for assessing the probability of the presence of osteopenic syndrome in this category of patients.
Disclosure of Interest: None declared

DOI: 10.1136/annrheumdis-2017-eular.1125

\section{AB0825 COMPARISON OF BONE DENSITY CHANGES ONE YEAR AFTER TREATMENT WITH ZOLEDRONIC ACID VERSES DAILY TERIPARATIDE}

A.K. Aggarwal, D. Jain, N. Aggarwal. Rheumatology, Institute of Rheumatology \& Pain, Ghaziabad, India

Background: The treatment of Osteoporosis is difficult to monitor and so usually incomplete resulting in inadequate response. ${ }^{1}$

Objectives: To evaluate the minimum period of treatment required with Bisphosphonates and Parathyroid hormone in order to see a significant change in serial Bone Mineral Density analysis (BMD).

Methods: Low BMD patients were subjected to yearly infusion of Zoledronic Acid $5 \mathrm{mg}(\mathrm{ZA})$ verses daily Subcutaneous injections of Teriparatide $20 \mu \mathrm{g}$ (PTH). A single center pencil beam bone densitometer was used to measure serial BMD at baseline and yearly. Average BMD measures from the Spine L2, L3 and L4 (BS) and Total Hip (BH) were evaluated. The percentage change in the mean BS and $\mathrm{BH}$ readings was calculated to look for the least significant change (LSC) in the density scores.

Results: Significant change of $4.65 \%$ was seen $(\mathrm{LSC}=2.6 \%)^{2}$ in the Spine in the PTH group after one year of treatment while it took two years in the ZA group for a $2.77 \%$ change. There was no significant change $(\mathrm{LSC}=3.6 \%)^{2}$ in both groups in the BH. A p $>0.05$ was considered statistically significant. The finding is summarized in Table 1.

Table 1

\begin{tabular}{|c|c|c|c|c|c|c|c|c|}
\hline \multicolumn{5}{|c|}{ Study group of 100 patients } & \multicolumn{4}{|c|}{ Percentage Change in BMD } \\
\hline \multirow[t]{2}{*}{ Treatment Group } & \multirow[t]{2}{*}{$\mathrm{N}$} & \multicolumn{2}{|c|}{ Gender } & \multirow{2}{*}{$\begin{array}{c}\text { Age range } \\
\text { Years }\end{array}$} & \multicolumn{2}{|c|}{$\mathrm{BS}^{*}$} & \multicolumn{2}{|c|}{$\mathrm{BH}^{\star \star}$} \\
\hline & & Males & Female & & After $1 \mathrm{yr}$ & After 2 yrs & After $1 \mathrm{yr}$ & After 2 yrs \\
\hline d & 50 & 12 & 38 & $42-79$ & 2.19 & 2.77 & 0.02 & 2.47 \\
\hline PTH -Teriparatide & 50 & 10 & 40 & $40-75$ & 4.651 & $\mathrm{x}$ & 2.272 & $\mathrm{x}$ \\
\hline \multicolumn{5}{|c|}{ LSC - Least Significant Change for single DXA machine } & \multicolumn{2}{|c|}{$2.50 \%$} & \multicolumn{2}{|c|}{$3.60 \%$} \\
\hline
\end{tabular}

${ }^{\star}$ Average of L2,3,4 Spine; *^Total Hip.

Conclusions: Significant result of treatment with $\mathrm{PTH}$ requires a period of one year of therapy while with ZA it needs two years. The LSC in BMD is seen in the Spine and not in the Total Hip BMD.

\section{References:}

[1] Glen M. Blake, Ignac Fogelman. Role of Dual-Energy X-Ray Absorptiometry in the Diagnosis and Treatment of Osteoporosis.

[2] Shepherd JA1, Lu Y. A generalized least significant change for individuals measured on different DXA systems.

Disclosure of Interest: None declared

DOI: 10.1136/annrheumdis-2017-eular.3198

\section{AB0826 RESULTS OF BONE MINERAL DENSITY IN COELIAC DISEASE: ABOUT 30 CASES}

H. Kchir ${ }^{1}$, D. Kaffel ${ }^{2}$, R. Zgolii ${ }^{1}$, D. Issaoui ${ }^{1}$, H. Chaabouni ${ }^{1}$, H. Sahli ${ }^{3}$, N. Maamouri ${ }^{1}$, M. Elleuch ${ }^{3}$, M.M. Kchir ${ }^{2}$, N. Ben Mami ${ }^{1}$. ${ }^{1}$ gastroenterology B, Rabta hospital, Tunis; ${ }^{2}$ Rheumatology, Kassab institute, Manouba;

${ }^{3}$ Rheumatology, Rabta hospital, Tunis, Tunisia

Background: The link between Coeliac disease (CD) and low bone mass has been established in several large international studies.

Objectives: To determinate the prevalence and risk factors of osteopenia and osteoporosis in a Tunisian population of coeliac patients.

Methods: We carried a retrospective study from January 1991 to December 2015 including all cases of CD diagnosed in the departement of Gastroenterology B in Rabta's Hospital. We retained all patients having a bone mineral density (BMD). We used the WHO criteria for the diagnosis of osteoporosis and osteopenia.

Results: During the period of the study, 78 cases of CD were included. Thirty among them, performed a BMD: 25 women and 5 men with an average age of 35.8 years. Malnutrtion was found in 14 patients with a BMI $<20 \mathrm{Kg} / \mathrm{m}^{2}$. Smoking was found in one case. Among women, 2 were menopaused. BMD showed a low bone mass in $76,3 \%$ of patients: osteoporosis in $43.3 \%$ and osteopenia in $33.3 \%$. The mean T score was -2.08 DS in the lumabr spine (LS) and -1DS in the Femur (F). The mean Z score was -1.66DS in LS and -0.73DS in femur. Osteoporosis was found in 13 patients: 3 men and 10 women ( 2 among them were menopaused). The research of risk factors of osteoporosis found a smoking $(\mathrm{N}=1)$, and an associated autoimmune disease in 5cases: A diabetes Mellitus in 3 patients, and an autoimmune hepatitis an Sjogren Syndrome in 1 case. Finally, a marked villous atrophy was associated to osteoporosis in 9 cases.

Conclusions: Our study showed that approximately $3 / 4$ of coeliac patients had a low bone mass. Osteoporosis was found in $33 \%$ of our patients and was associated to a marked villous atrophy.

Disclosure of Interest: None declared

DOI: 10.1136/annrheumdis-2017-eular.6923 